\title{
Cholecystokinin Potentiates Dopamine-mediated Behaviors: Evidence for Modulation Specific to a Site of Coexistence ${ }^{1}$
}

\author{
JACQUELINE N. CRAWLEY, ${ }^{2}$ JILL A. STIVERS, LISA K. BLUMSTEIN, ${ }^{\star}$ AND STEVEN M. PAUL \\ Clinical Neuroscience Branch, National Institute of Mental Health, Bethesda, Maryland 20205 and *Neurobiology Program, Central \\ Research and Development Department, E. I. DuPont de Nemours and Company, Inc., Glenolden, Pennsylvania 19036
}

\begin{abstract}
Cholecystokinin coexists with dopamine in mesolimbic neurons in mammalian brain. When injected directly into the nucleus accumbens, cholecystokinin (CCK) potentiated dopamine (DA)-induced hyperlocomotion and apomorphine-induced stereotypy. These effects were not mimicked by nonsulfated CCK, but were blocked by proglumide, a putative CCK antagonist, as well as by antisera raised against sulfated CCK. CCK alone had no effect on locomotion or stereotypy, indicating that this peptide acts primarily as a modulator of DA-mediated behaviors in the mesolimbic pathway. In addition, CCK did not potentiate DA-induced hyperlocomotion or apomorphine-induced stereotypy when injected into the caudate nucleus, where CCK and DA are localized in separate neurons in rats. Facilitation of DA-mediated behaviors by CCK may represent a functional interaction specific to the neuromodulator-neurotransmitter coexistence phenomenon.
\end{abstract}

Several recent immunocytochemical studies suggest that cholecystokinin (CCK) is co-localized in the same neurons as dopamine (DA) in the mesolimbic pathway of the rat. Immunofluorescence micrographs from ventral tegmental sections incubated with antisera to gastrin/CCK and subsequently to tyrosine hydroxylase showed identity between CCK-immunoreactive neurons and DA-immunorcactive ncurons (Hökfelt ct al., 1980a). Combined immunocyto chemistry and retrograde tracing of fluorescent dyes showed CCK/ DA-containing cell bodies in the ventral tegmental area projecting to the caudal, medial nucleus accumbens (Hökfelt et al., 1980b), amygdala, and olfactory tubercles (Fallon et al., 1983). Injection of 6-hydroxydopamine into the ventral mesencephalon produced a parallel reduction in both tyrosine hydroxylase immunoreactivity and gastrin/CCK immunoreactivity (Hökfelt et al., 1980b; Studler et al., 1981; Marley et al., 1982).

Functional studies indicate interactions between CCK and DA in vitro and in vivo. DA potentiated veratridine-induced release of CCK (Meyer and Krauss, 1983), whereas CCK inhibited release of DA from cat caudate nucleus (Markstein and Hökfelt, 1984) and rat nucleus accumbens (Voight and Wang, 1984), while stimulating

Received June 28, 1984; Revised January 10, 1985

Accepted January 14, 1985

\footnotetext{
${ }^{1}$ We wish to thank Drs. Tomas Hökfelt, Lana Skirboll, and Dan Hommer for their inspiration and insightful discussions throughout these studies. Mrs. June Zuranski provided excellent technical assistance in the preparation of the manuscript. Gifts of compounds from Dr. Marge Beinfeld and The A. H. Robins Co. are greatly appreciated.

${ }^{2}$ To whom correspondence should be addressed.
}

release of DA from rat striatum (Chesselet, 1984) and mouse striatum (Kovacs et al., 1981). In addition, CCK reduced DA turnover in the nucleus accumbens and caudate nucleus of the rat (Fuxe et al., 1980). CCK levels in the striatum and mesolimbic system increased after chronic DA receptor blockade (Frey, 1983). DA-binding sites in the cerebral cortex and olfactory tubercles showed an increase in number and a decrease in affinity after CCK treatment (Murphy and Schuster, 1982; Agnati et al., 1983).

Neurophysiological studies of extracellular recording from the ventral tegmental neurons and the nucleus accumbens found that CCK enhances the inhibition of neuronal firing induced by DA and apomorphine (APO), even though CCK is excitatory when administered alone (Hommer and Skirboll, 1983; Crawley et al., 1984; DeFrance et al., 1984). Taken together, these several lines of evidence support the concept that CCK coexists with DA in the mesolimbic system, functioning as a modulator of dopaminergic activity.

Although the behavioral actions of peripheral CCK on digestive processes and food intake have been elaborated (Mutt, 1978; Smith and Gibhs, 1981; Morley, 1982; Crawley et al., 1982), the behavioral functions of central CCK remain obscure. High doses of CCK, injected intraventricularly, decrease open field behaviors (Van Ree et al., 1983; Katsuura et al., 1984), suppress operant responding (Cohen et al., 1983), and induce sedation and catalepsy (Zetler, 1980, 1982). However, these effects may be of peripheral origin, since the microgram doses of CCK employed in these studies are likely to enter the systemic circulation (Passaro et al., 1982). Intrathecal adrinistration of the CCK anlagonist, proglumide, potentiated opiate analgesia, suggesting that in the spinal cord CCK may modulate opiate function (Faris et al., 1983; Watkins et al., 1984).

Since the mesolimbic DA pathway has been shown to have relatively specific behavioral actions on locomotion (Creese and Iversen, 1974; Iversen, 1977) and also plays a role in the induction of stereotypy (Costall and Naylor, 1975; Costal et al., 1977; Joyce, 1983), CCK might be expected to elicit the same set of motor behaviors when injected into the nucleus accumbens. Studies using high doses of CCK found no direct effect of CCK on stereotypy or locomotion (Schneider et ał., 1983; Widerlov et al., 1983; Hamilton et al., 1984). Microgram doses of CCK injected into the nucleus accumbens were found to inhibit amphetamine-induced hyperlocomotion (Schneider et al., 1983) and APO-induced stereotypy (Ellinwood et al., 1983). However, physiologically relevant doses of CCK have not been tested in the nucleus accumbens for their behavioral effects.

The studies presented here were undertaken to provide a systematic behavioral analysis of a wide range of doses of CCK injected directly into the nucleus accumbens. The effects of CCK administered alone, of CCK administered in conjunction with DA, and of CCK administered in conjunction with APO were tested on both the hyperlocomotion paradigm and the stereotypy paradigm. In addition, since CCK in the substantia nigra and in the caudate nucleus 
appears to be localized in a population of neurons separate from those containing DA (Hökfelt et al., 1980b; Marley et al., 1982; Gilles et al., 1983), the effects of CCK alone and in conjunction with DA or APO on stereotypy and hyperlocomotion were also tested in the caudate nucleus.

\section{Materials and Methods}

Male Sprague-Dawley rats, 200 to $250 \mathrm{gm}$, were stereotaxically implanted with indwelling guide cannulae into the nucleus accumbens or caudate nucleus, under sodium pentobarbital anesthesia. Hypodermic stainless steel tubing, 24 gauge (Small Parts Inc., Miami, FL), was bilaterally placed into the nucleus accumbens according to the stereotaxic coordinates of Paxinos and Watson (1982) and the sites of coexisting CCK and DA terminals described by Hökfelt et al. (1980b): $1.2 \mathrm{~mm}$ anterior to bregma, $\pm 1.2 \mathrm{~mm}$ lateral to the sagittal suture, and $5.7 \mathrm{~mm}$ ventral to bregma, with the mouthbar at -3.5 $\mathrm{mm}$. Hypodermic stainless steel tubing, 24 gauge, was bilaterally placed into the caudate nucleus according to the stereotaxic coordinates of Paxinos and Watson (1982): anterior-posterior coordinate at bregma, $\pm 3.5 \mathrm{~mm}$ lateral to the sagittal suture, and $6.0 \mathrm{~mm}$ ventral to bregma. The ventral coordinates were $1.0 \mathrm{~mm}$ dorsal to the intended site of injection, to minimize potential damage to the target site by the implanted guide cannula. The injection tube, fabricated of 31 gauge hypodermic stainless steel, (Small Parts Inc.), was exactly $1.0 \mathrm{~mm}$ longer than the implanted guide cannula, such that the tip used for injection directly into the target site consisted of extremely fine gauge tubing.
Injection sites were histologically verified in each animal at the end of each experiment. Fast green dye, $0.2 \mu \mathrm{l} / \mathrm{min} /$ accumbens, or $0.5 \mu \mathrm{l} / \mathrm{min} /$ caudate, was injected, and brains were removed for frozen sectioning at $50 \mu \mathrm{m}$ and subsequent staining with cresyl violet. Approximately $5 \%$ of the placements directed at the nucleus accumbens and $2 \%$ of the placements directed at the caudate nucleus were erroneous. Data from animals with incorrect cannula placements were eliminated from the statistical analysis and are not included in the figures below.

Location of cannulae in the nucleus accumbens and caudate nucleus are represented in figure 1. The volume of injection was chosen from Myers (1966) to deliver a maximal spherical diameter of $0.5 \mathrm{~mm}$ for the nucleus accumbens and $1.0 \mathrm{~mm}$ for the caudate nucleus, to compensate for the larger spherical diameter of the caudate nucleus. The rate of injection was chosen to minimize tissue damage in the target site during injection.

All drug administration and behavioral testing was performed at least 1 week after surgical procedures for cannula implantation. Drug administration was performed by constant infusion of $0.2 \mu \mathrm{l} /$ nucleus accumbens site and $0.5 \mu \mathrm{l} /$ caudate nucleus site, over a 1-min time period/site. A Sage microinfusion pump (Orion Research, Inc., Cambridge, MA) advanced the plunger of a $10 \mu$ l-Hamilton syringe (PGC Scientifics Corp., Gaithersburg, MD), connected to PE-20 polyethylene tubing, attached to the injection tube. The following drugs were administered in the doses described below: CCK-8sulfate and CCK-8-nonsulfate (Bachem, Inc., Torrance, CA), proglumide (A. $\mathrm{H}$. Robins Co., Richmond, VA), preimmune rabbit serum and rabbit serum raised against sulfated CCK-8 (gift of Dr. Margery C. Beinfeld, Department

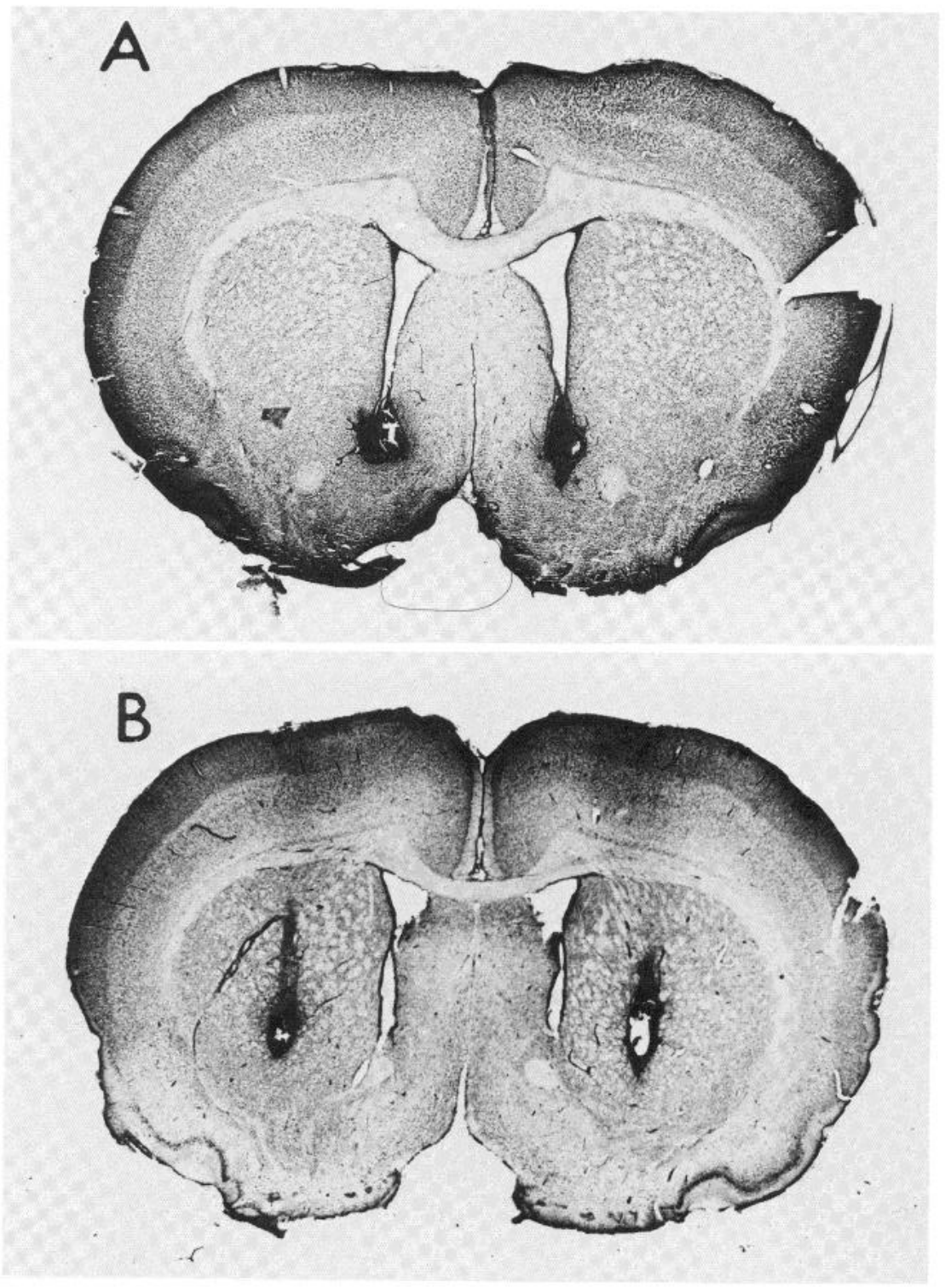

Figure 1. Location of indwelling 24 gauge hypodermic stainless steel cannulae, stereotaxically implanted in male Sprague-Dawley rats under pentobarbital anesthesia. $A$, Caudal ventral region of the nucleus accumbens. Terminals containing both CCK and DA, from ventral tegmental neurons in which CCK and DA co-exist, have been dem. onstrated in this region (Hökfelt et al., 1980a, b). B, Medial caudal caudate nucleus. Terminals containing either CCK or DA, from cortical or substantia nigra neurons which contain either CCK or DA, have been demonstrated in this region (Hökfelt et al., 1980a). In the nucleus accumbens, $0.2 \mu \mathrm{l}$ of $\mathrm{drug} / \mathrm{min}$ was injected through a 31 gauge hypodermic stainless steel injection tube in conscious rats. In the caudate nucleus, $0.5 \mu \mathrm{l}$ of drug/min was identically injected. Drug was injected immediately before behavioral testing. Fast green dye was injected under identical conditions before sacrifice at the end of each experiment. Histological analysis of the location of the cannula tip and spread of the injected fast green dye was performed at the end of each experiment. 
TABLE I

Animal testing paradigm for the four experiments ${ }^{a}$

\begin{tabular}{cllll}
\hline \multirow{2}{*}{ Test Day } & \multicolumn{4}{c}{ Group } \\
\cline { 2 - 5 } & \multicolumn{1}{c}{1} & \multicolumn{2}{c}{3} & \multicolumn{1}{c}{4} \\
\hline 1 & SAL $^{b}$ & DA & CCK & DA + CCK \\
2 & DA & CCK & DA + CCK & SAL \\
3 & CCK & DA + CCK & SAL & DA \\
4 & DA + CCK & SAL & DA & CCK \\
\hline
\end{tabular}

${ }^{a}$ In all studies, animals were used four times, with intervals of at least 4 days between uses, in a Latın Square Design (Fisher, 1950). See the text for details.

${ }^{\mathrm{D}} \mathrm{SAL}$, saline.

of Pharmacology, University of St. Louis School of Medicine, St. Louis, MO), and $0.9 \%$ physiological saline (Abbott Laboratories, Chicago, IL).

In all studies, animals were used four times, with intervals of at least 4 days between uses, in a Latin Square Design (Fisher, 1950). For example, in experiments 2 and 4 , animals were divided into four treatment groups: saline, DA, CCK, and DA + CCK, for each dose of CCK (Table I). On a given test day, locomotion scores for saline and DA were required to be not significantly different from scores obtained for saline and DA on previous test days for inclusion of the data on CCK and DA + CCK in the present study.

Two behavioral paradigms were employed. Ambulatory locomotion was quantitated over a 15-min test session in a photocell-equipped Digiscan Optical Animal Activity Monitor (Omnitech Electronics Co., Columbus, $\mathrm{OH}$ ). Stereotypy was scored over a 15 -min test session by a human observer who was uninformed of the drug treatment condition. Rats were individually placed in clear plastic cages, $18 \times 29 \times 13 \mathrm{~cm}$, and rated every $30 \mathrm{sec}$ for $15 \mathrm{~min}$ by the stereotypy rating scale of Creese and iversen (1974): $0=$ inactive; 1 = active; 2 = locomotion with bursts of stereotyped sniffing; $3=$ locomotion with continuous stereotyped sniffing or rearing; $4=$ stereotyped behavior maintained in one location; $5=$ stereotyped behavior in one location with bursts of gnawing, licking, or biting. Behavioral data were analyzed for slatistical significance by analysis of variance (ANOVA) followed by the Newman-Keuls a posteriori test for significance of individual means.

Experiment 1 analyzed the dose-response relationship for DA injected into the nucleus accumbens on hyperlocomotion, and for APO injected subcutaneously on stereotypy. DA $(10,20,30$, or $40 \mathrm{ng})$ or saline $(0.2 \mu \mathrm{l})$ was injected into each side of the nucleus accumbens, 1 min before scoring of ambulatory locomotion as described above. APO $(0.1,0.15,0.2,0.3$, or 0.4 $\mathrm{mg} / \mathrm{kg}$ ) or saline $(0.2 \mathrm{ml})$ was injected subcutaneously $15 \mathrm{~min}$ before scoring of stereotypy as described above. These doses were chosen from previous studies (Pijnenburg and Van Rossum, 1973; Costall and Naylor, 1975; Iversen, 1977; Joyce, 1983), to determine the optimal doses of DA and apomorphine for clicitation of hypcrlocomotion and stcrcotypy, respectively.

Experiment 2 investigated the effects of CCK on ambulatory locomotor activity. CCK $(2,20$ or $200 \mathrm{pg} ; 2,20$, or $200 \mathrm{ng})$ or saline, in $0.2 \mu \mathrm{l}$, was bilalerally injected over a 1 -rin period into the nucleus accurnbens as described above. CCK $(4,40$, or $400 \mathrm{pg}$; or 4,40 , or $400 \mathrm{ng}$ ) or saline, in $0.5 \mu$, was bilaterally injected over a $1-\mathrm{min}$ period into the caudate nucleus. One minute after injection, rats were placed into the Digiscan activity monitor for $15 \mathrm{~min}$, as described above.

Experiment 3 investigated the effects of CCK on stereotyped behavior. CCK $(2,20$, or $200 \mathrm{pg} ; 2,20$, or $200 \mathrm{ng} ;$ or $2 \mu \mathrm{g}$ ) or saline, in $0.2 \mu \mathrm{l}$, was injected bilaterally over a 1-min period into the nucleus accumbens, as described above. CCK $(4,40$, or $400 \mathrm{pg}$; or 4,40 , or $400 \mathrm{ng}$ ) or saline, in $0.5 \mu \mathrm{l}$, was injected bilaterally over a 1 -min period into the caudate nucleus, as described above. Stereotyped sniffing, gnawing, and licking were scored for $15 \mathrm{~min}$, beginning $1 \mathrm{~min}$ after injection, as described above.

Experiment 4 investigated the effects of CCK on DA-induced hyperlocomotion. CCK $(2,20$, or $200 \mathrm{pg} ; 2,20$, or $200 \mathrm{ng}$; or $2 \mu \mathrm{g})$ or saline was combined with DA $(20 \mu \mathrm{g} / 0.2 \mu)$ and injected bilaterally over a 1 -min period into the nucleus accumbens, as described above. CCK $(4,40$, or $400 \mathrm{pg}$; or 4,40 , or $400 \mathrm{ng})$ or saline was combined with DA $(20 \mu \mathrm{g} / 0.5 \mu \mathrm{l})$ and injected bilaterally over a 1 -min perıod into the caudate nucleus, as described above. One minute after injection, rats were placed into the Digiscan activity monitor for $15 \mathrm{~min}$, as described above.

Experiment 5 investigated the effects of CCK on APO-induced stereotypy. CCK $(2,20$, or $200 \mathrm{pg} ; 2,20$, or $200 \mathrm{ng}$; or $2 \mu \mathrm{g})$ or saline was injected bilaterally over a 1-min period into the nucleus accumbens, 12 min after subcutaneous injection of APO $(0.2 \mathrm{mg} / \mathrm{kg})$. CCK $(4,40$, or $400 \mathrm{pg}$; or 4 , 40 , or $400 \mathrm{ng}$ ) or saline was injected bilaterally over a 1 -min period into the caudate nucleus, $12 \mathrm{~min}$ aftor subcutancous injection of APO $(0.2 \mathrm{mg} / \mathrm{kg})$. Stereotyped sniffing, gnawing, and licking were scored for $15 \mathrm{~min}$, beginning $15 \mathrm{~min}$ after apomorphine injection and $1 \mathrm{~min}$ after intracerebral injection.

Experiment 6 investigated the aclivily of unsulfated CCK-8 as compared to sulfated CCK-8 on DA-induced hyperlocomotion and APO-induced stereotypy after peptide injection into the nucleus accumbens. Unsulfated CCK or sulfated CCK ( $2 \mathrm{ng}$ or $2 \mu \mathrm{g}$ ), or saline was injected bilaterally into the nucleus accumbens, in conjunction with DA $(20 \mu \mathrm{g})$ into the nucleus accumbens, or in conjunction with APO $(0.2 \mathrm{mg} / \mathrm{kg}$, s.c.), as described in experiments 4 and 5.

Experiment 7 investigated the ability of proglumide and of antiserum raised against sulfated CCK-8 to block the effects of CCK on DA-induced hyperlocomotion. CCK $(200 \mathrm{pg})+\mathrm{DA}(20 \mu \mathrm{g})$, CCK $(200 \mathrm{pg})$, or saline was bilaterally injected in a volume of $0.2 \mu$ over a 1 -min period into the nucleus accumbens, $5 \mathrm{~min}$ after administration of (a) proglumide $(8$ or $20 \mu \mathrm{g}),(b)$ preimmune serum, undiluted; $(c)$ antiserum to $C C K$, undiluted or diluted $1: 5$ with $0.9 \% \mathrm{NaCl}$; or $(d)$ saline, in a volume of $0.2 \mu$, bilaterally over a 1 -min period, into the nucleus accumbens.

\section{Results}

Figure $2 A$ shows the dose-response curve for DA injected into the nucleus accumbens on locomotor activity. ANOVA yielded a significant effect of dose: $F_{4,20}=9.83, p<0.01$. Newman-Keuls a posteriori analysis for significance of individual means showed a significant increase in locomotion after doses 20,30, and $40 \mu \mathrm{g}$ of DA injected bilaterally into each nucleus accumbens $\left({ }^{\star \star} p<0.01\right)$, as compared to saline controls ( $N=5$ for each dose); data are represented as mean \pm SEM. A dosc of $20 \mu \mathrm{g} / \mathrm{side}$ was chosen, to employ a dose of DA which significantly increased locomotion without approaching a maximal response. Figure $2 B$ shows the dose-response curve for apomorphine injected subcutaneously on stereotyped sniffing behaviors. ANOVA yielded a significant effect of dose: $F_{5,25}=11.45, p<0.01$. Newman-Keuls analysis showed a significant increase in stereotypy score after doses of $0.10,0.15$, $0.2,0.3$, and $0.4 \mathrm{mg} / \mathrm{kg}$ of APO subcutaneously, as compared to saline controls $\left({ }^{*} p<0.05 ;{ }^{* *} p<0.01 ; N=5\right.$ for each dose; data represented as mean \pm SEM). A dose of $0.2 \mathrm{mg} / \mathrm{kg}$, s.c., was chosen as approximately half-maximal from this curve, to employ a dose of APO which significantly increased stereotypy without approaching a maximal response.

Figure $3 A$ shows the lack of effects of CCK on locomotor activity when injected into the nucleus accumbens over the dose range of $2 \mathrm{pg}$ to $200 \mathrm{ng} / \mathrm{side}$, as compared to saline-injected controls (ANOVA: $F_{5,25}=1.41$, not significant; $N=5$ for each dose). Figure $3 B$ shows the lack of effect of CCK on locomotor activity when injected into the caudate nucleus over the dose range of $4 \mathrm{pg}$ to $400 \mathrm{ng} /$ side, as compared to saline-injected controls (ANOVA: $F_{5,27}=1.54$, not significant; $N=5$ for each dose).

Figure $4 A$ shows the lack of effect of CCK on stereotypy scores when injected into the nucleus accumbens over the dose range of $2 \mathrm{pg}$ to $2 \mu \mathrm{g} / \mathrm{side}$, as compared to saline-injected controls (ANOVA: $F_{6,28}=2.25$, not significant; $N=5$ for each dose). Figure $4 B$ shows the lack of effect of CCK on stereotypy when injected into the caudate nucleus over the dose range of $4 \mathrm{pg}$ to $400 \mathrm{ng} / \mathrm{side}$, as compared to saline-injected controls (ANOVA: $F_{5,23}=2.61$, not significant; $N=5$ for each dose).

Figure $5 A$ shows a significant effect of CCK on DA-induced hyperlocomotion when CCK was injected in combination with DA into the nucleus accumbens. CCK significantly increased the locomotion scores at doses from $20 \mathrm{pg}$ to $200 \mathrm{ng} / \mathrm{side}$ when administered with DA (20 $\mu \mathrm{g} / \mathrm{side})$, as compared to DA (20 $\mu \mathrm{g} / \mathrm{side})+$ saline (ANOVA: $F_{6,48}=4.46, p<0.01$; Newman-Keuls ${ }^{*} p<0.05$, ${ }^{\star \star} p<0.01 ; N=8$ for each dose). Figure $5 B$ shows that CCK had no effect on locomotion when injected in combination with DA into the caudate nucleus in CCK doses of from $4 \mathrm{pg} / \mathrm{side}$ to $400 \mathrm{ng} /$ side + DA (20 $\mu \mathrm{g} / \mathrm{side})$, as compared to DA (20 $\mu \mathrm{g} / \mathrm{side})+$ saline (ANOVA: $F_{5.42}=1.54$, not significant; $N=8$ for each dose).

Figure $6 A$ shows a significant effect of CCK on APO-induced stereotypy when CCK was injected into the nucleus accumbens 15 min after subcutaneous injection of APO. CCK significantly increased 


\section{A) DOSE-RESPONSE FOR DOPAMINE-INDUCED HYPERLOCOMOTION IN THE NUCLEUS ACCUMBENS}
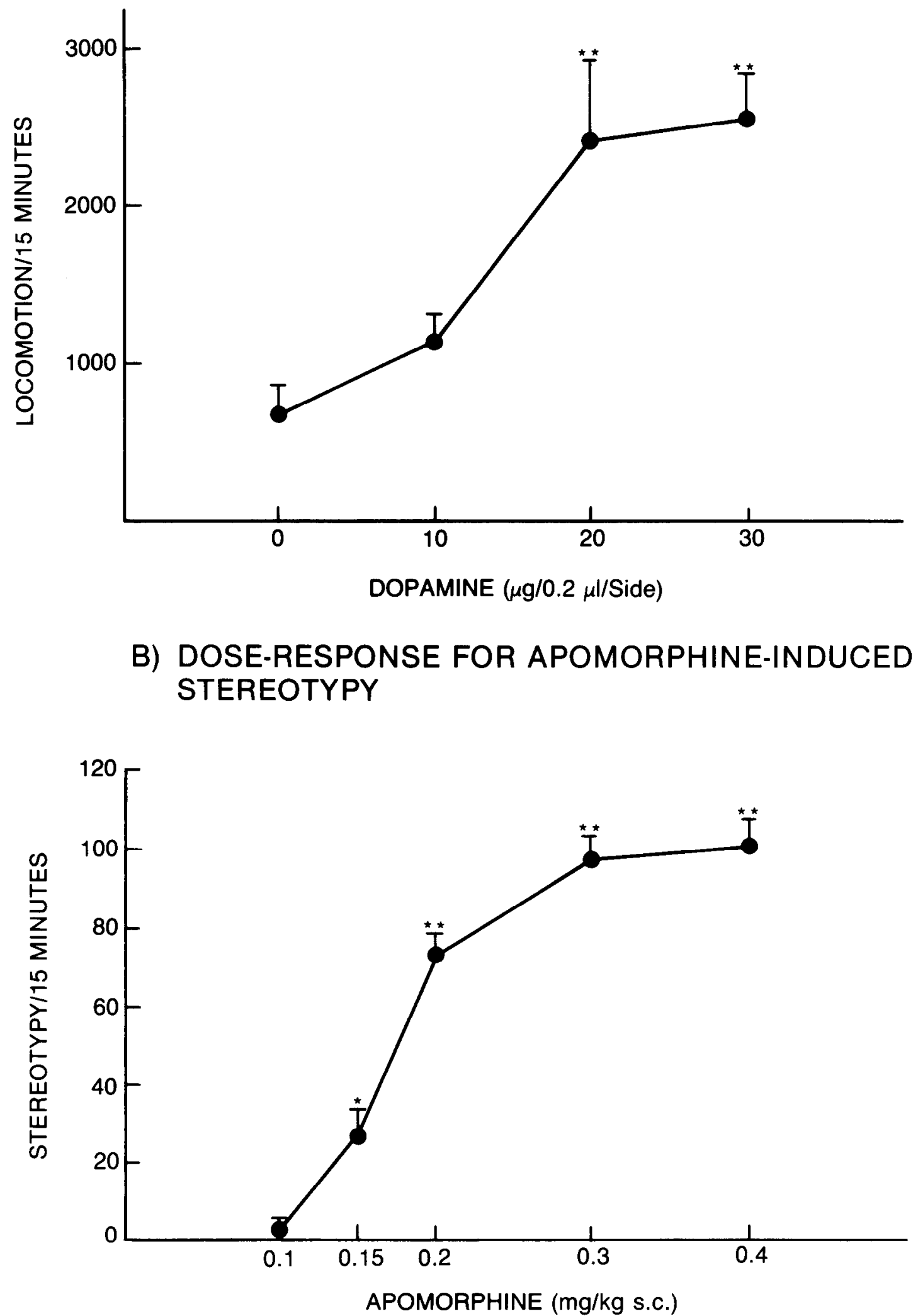

Figure 2. Dose-response relationship for DA injected into the nucleus accumbens on the elicitation of hyperlocomotion $(A)$ and for APO injected subcutaneously on the elicitation of stereotyped behaviors $(B)$. Data are represented as mean \pm SEM. $N=5$ for each dose of each treatment $*, p<0.05$; **, $\rho<0.01$, by Newman-Keuls analysis of significance of individual means, as compared to saline-treated controls, following a significant value for ANOVA. 

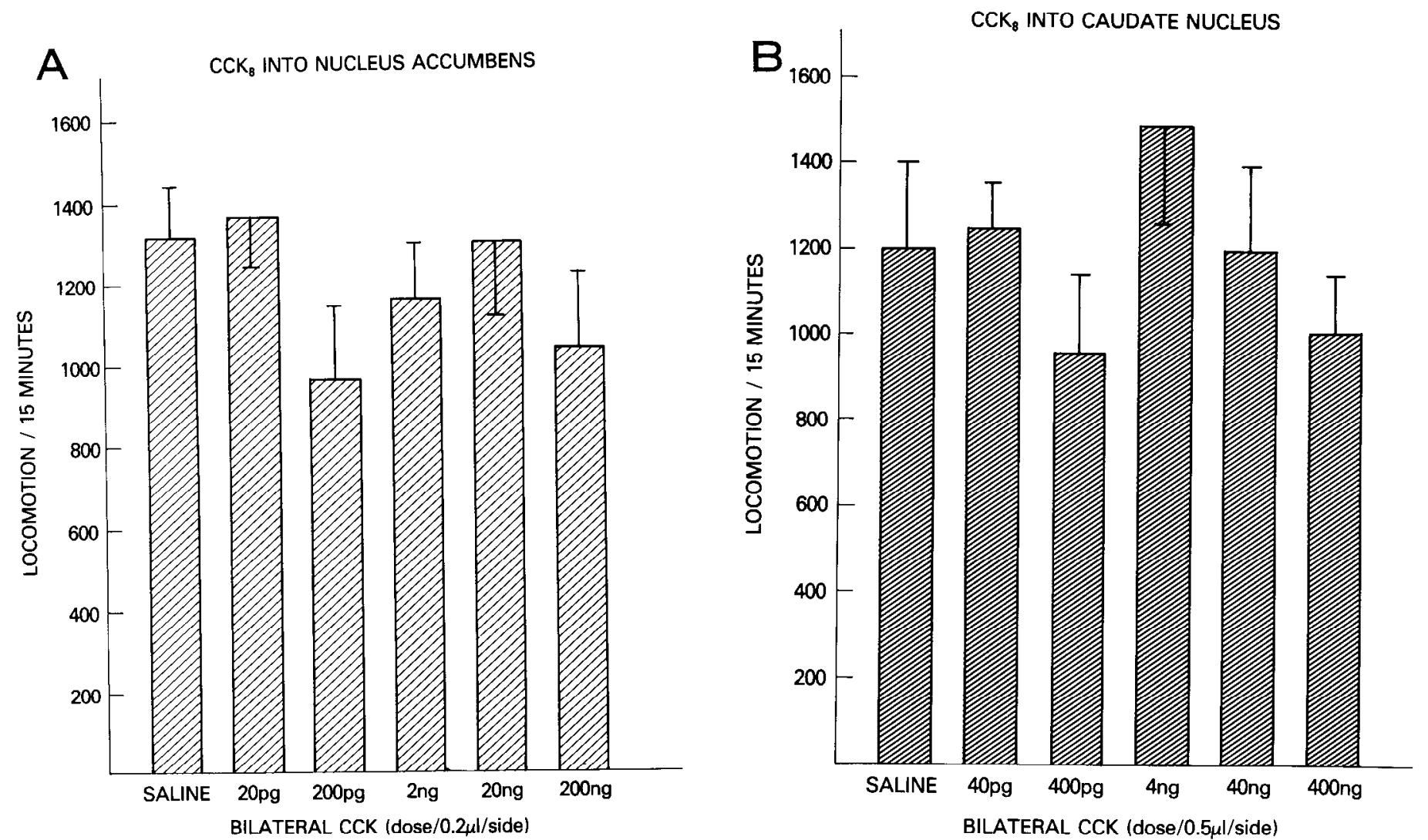

Figure 3. A, CCK had no effect on locomotor activity when injected into the nucleus accumbens over the dose range of 2 pg to 200 ng/nucleus accumbens, as compared to saline-injected controls. $B$, CCK had no effect on locomotor activity when injected into the caudate nucleus over the dose range of $4 \mathrm{pg}$ to $400 \mathrm{ng} /$ caudate nucleus, as compared to salıne-Injected controls. $N=5$ for each dose of each treatment.

the stereotypy scores at doses from $20 \mathrm{pg}$ to $200 \mathrm{ng} / \mathrm{side}$ when administered after APO $(0.2 \mathrm{mg} / \mathrm{kg}$, s.c.), as compared to APO $(0.2$ $\mathrm{mg} / \mathrm{kg}$, s.c.) + saline (ANOVA: $F_{6.48}=7.64, p<0.01$; NewmanKeuls ${ }^{\star} p<0.05,{ }^{\star *} p<0.01 ; N=8$ for each dose). Figure $6 B$ shows that CCK had no effect on stereotypy when injected into the caudate nucleus 15 min after subcutaneous injection of APO. Doses of CCK from $40 \mathrm{pg}$ to $400 \mathrm{ng} / \mathrm{side}$ following APO $(0.2 \mathrm{mg} / \mathrm{kg}$, s.c. $)$ were not significantly different from APO $(0.2 \mathrm{mg} / \mathrm{kg}$, s.c.) + saline (ANOVA: $F_{5.41}=1.93$, not significant; $N=8$ for each dose).

Figure 7 shows the lack of effect of unsulfated CCK-8 on DAinduced hyperlocomotion and APO-induced stereotypy in the nucleus accumbens. Illustrated are the significant effects of CCKsulfated (2 ng/side) on DA-induced hyperlocomotion and APOinduced stereotypy, using groupcd $t$ tcst statistics to compare DA + CCK to DA + saline, and APO + CCK to APO + saline $\left({ }^{*} p<\right.$ 0.05 ). CCK-nonsulfated did not produce an effect on DA-induced hyperlocomotion or APO-induced stereotypy when injected into the nucleus accumbens in a dose of $2 \mathrm{ng} / \mathrm{side}$, as compared to DA + saline or to APO + saline by grouped $t$ test statistics. Sincc the affinity of CCK-nonsulfated is approximately 1000 -fold less than CCK-sulfated for the pancreatic CCK receptor (Gardner et al, 1977; Innis and Snyder, 1980), and since controversy exists on the relative affinities of CCK-nonsulfated and CCK-sulfated for the brain CCK receptor (Hays et al., 1980, Innis and Snyder, 1980; Saito et al., 1980; Praissman et al., 1983, Van Dijk, et al., 1984), a dose of CCKnonsulfated which was 1000-fold higher than the active dose of CCK-sulfated was also tested. CCK-nonsulfated did not produce an effect on DA-induced hyperlocomotion or APO-induced stereotypy when injected into the nucleus accumbens in a dose of $2 \mu \mathrm{g} / \mathrm{side}$, as compared to DA + saline or APO + saline by grouped $t$ test statistics. As found in experiments 4 and 5 , presented in Figures $5 \mathrm{~A}$ and $6 A$, CCK-sulfated had no effect on DA-induced hyperlocomotion or APO-induced stereotypy when injected into the nucleus accum- bens in a dose of $2 \mu \mathrm{g} / \mathrm{side}$, as compared to DA + saline or APO + saline by grouped $t$ test statistics $(N=6$ for each dose of treatment, $p<0.05$ ).

Figure $8 A$ shows the ability of the relatively specific CCK receptor antagonist, proglumide, to block the effects of CCK on DA-induced hyperlocomotion. Proglumide ( 8 or $20 \mu \mathrm{g} / \mathrm{side}$ ) + saline had no effect on base line locomotion (ANOVA: $F_{2.15}=1.33$, not significant), as compared to saline + saline. Proglumide ( 8 and $20 \mu \mathrm{g} / \mathrm{side}$ ) had no effect on DA induced hyperlocomotion (ANOVA: $F_{2,15}=1.67$, not significant), as compared to saline + DA (20 $\mu \mathrm{g} / \mathrm{side})$. Proglumide $(20 \mu \mathrm{g} / \mathrm{side})$ significantly inhibited the CCK-induced increase in DA-induced hyperlocomotion $\left(F_{2.15}=5.21, p<0.05\right.$; NewmanKeuls ${ }^{*} p<0.05$ for proglumide, $20 \mu \mathrm{g} / \mathrm{side}$ ), as compared to saline + DA $(20 \mu \mathrm{g} / \mathrm{side})+\mathrm{CCK}(200 \mathrm{pg} / \mathrm{side})(N=6$ for cach dose of each treatment). Figure $8 B$ shows the ability of rabbit antiserum raised against CCK-8-sulfated to block the effects of CCK on DAinduced hyperlocomotion. Undiluted preimmune serum, undiluted CCK antiserum, and CCK antiserum diluted 1:5 had no effect on base line locomotion (ANOVA: $F_{3,20}=0.98$, not significant), as compared to saline + saline. Undiluted preimmune serum, undiluted CCK antiserum, and 1:5 diluted CCK antiserum had no significant effect on DA-induced hyperlocomotion $\left(F_{3,20}=2.36\right.$, not significant), as compared to saline + DA ( $20 \mu \mathrm{g} / \mathrm{side})$. CCK antiserum, undiluted and diluted 1:5, significantly inhibited the CCK-induced increase in DA-induced hyperlocomotion $\left(F_{3,20}=7.24, p<0.01\right.$; NewmanKeuls $\left.{ }^{*} p<0.05\right)$, as compared to saline + DA $(20 \mu \mathrm{g} / \mathrm{side})+\mathrm{CCK}$ (200 pg/side). Preimmune serum had no effect on the CCK-induced increase in DA-induced hyperlocomotion $(N=6$ for each dose of each treatment).

\section{Discussion}

CCK was found to potentiate the behavioral effects of intracerebrally administered DA on locomotor activity and to potentiate the 


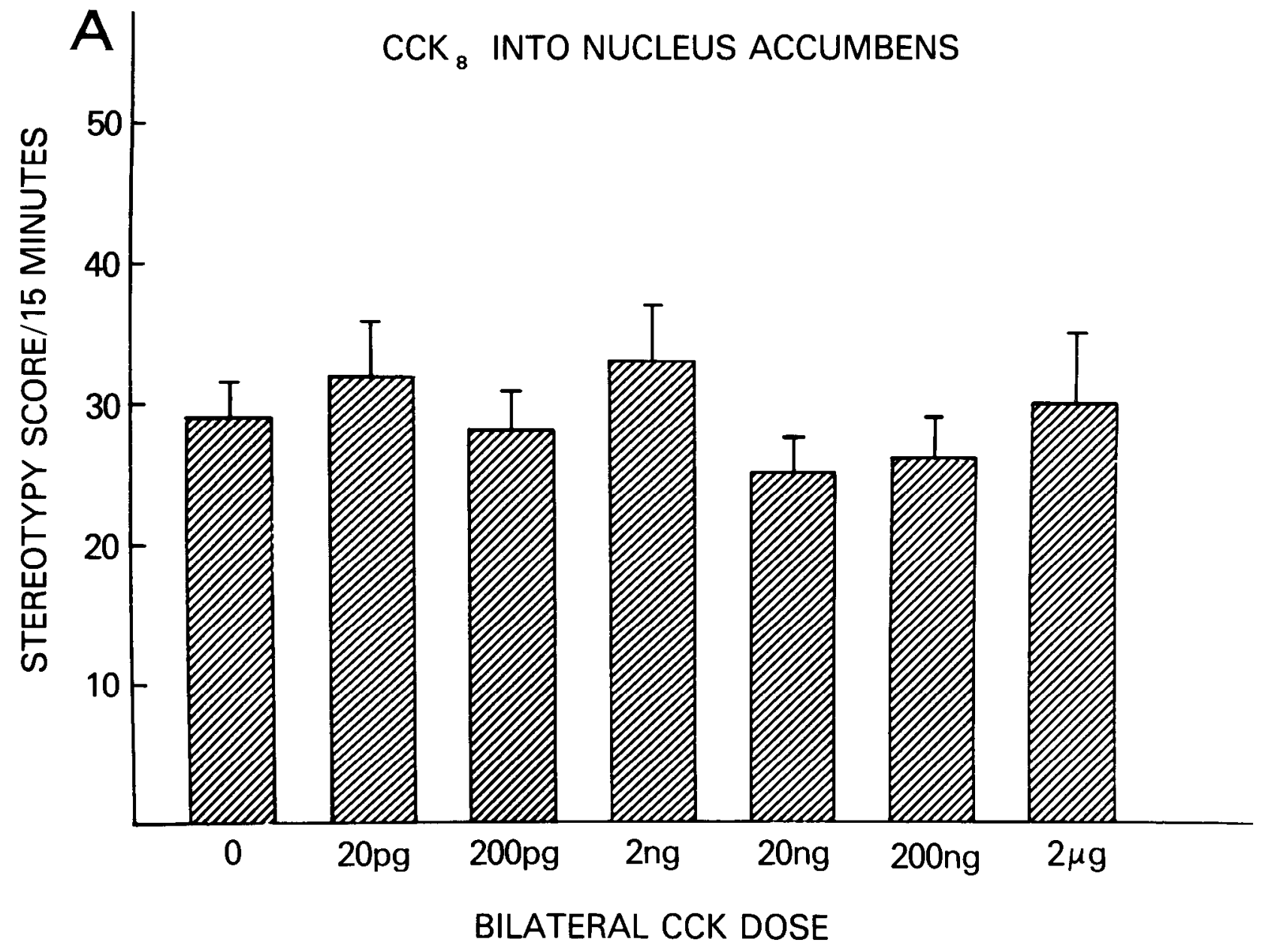

$\mathrm{CCK}_{\mathbf{8}}$ INTO CAUDATE NUCLEUS

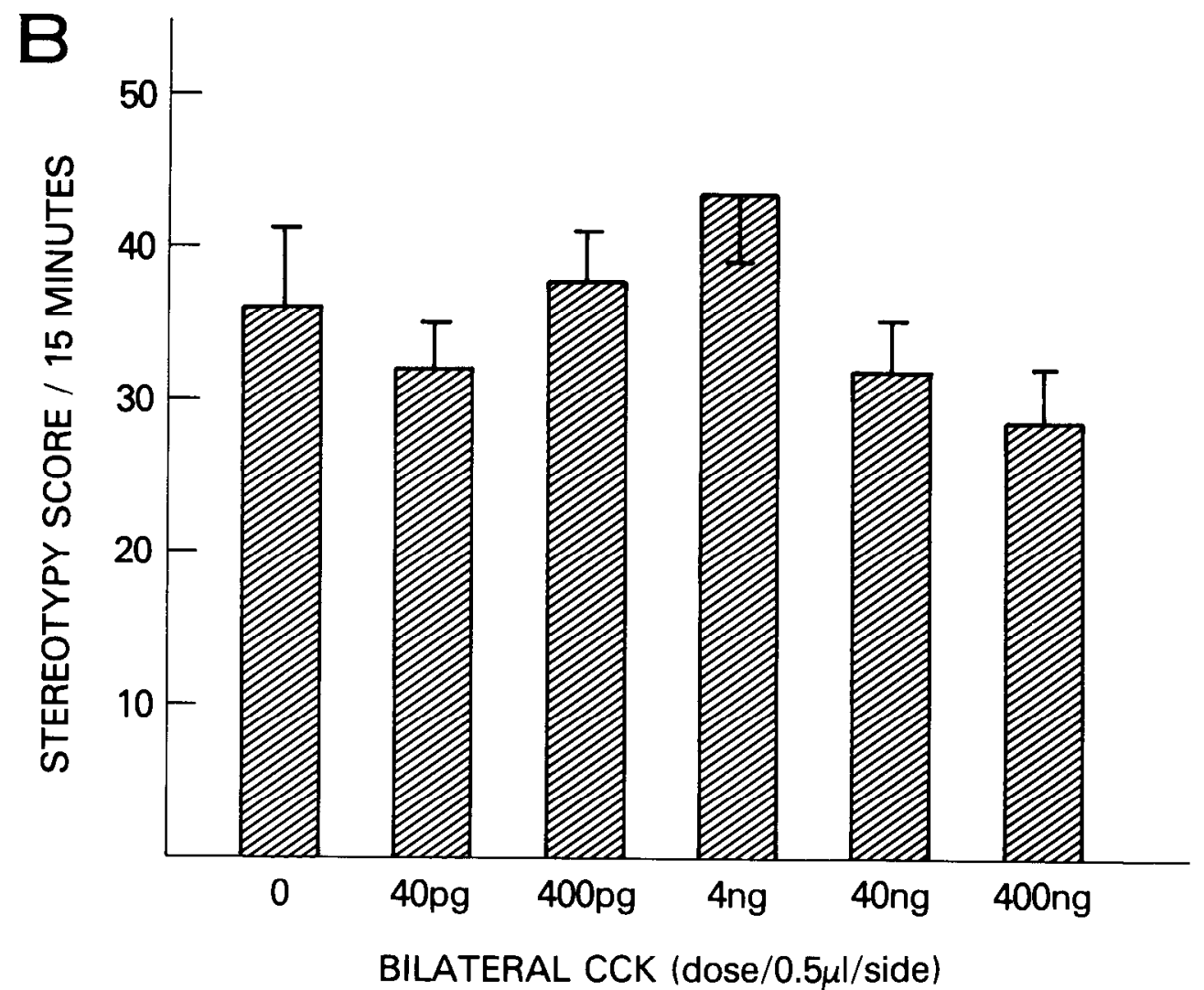

Figure 4. A, CCK had no effect on stereotypy scores when injected into the nucleus accumbens over the dose range of $2 \mathrm{pg}$ to $2 \mu \mathrm{g} / \mathrm{side}$, as compared to saline-injected controls. $B$, CCK had no effect on sterentypy scores when injected into the caudate nucleus over the dose range of 1 pg to 400 ng/side, as compared to saline-injected controls. $N=5$ for each dose of each treatment. 

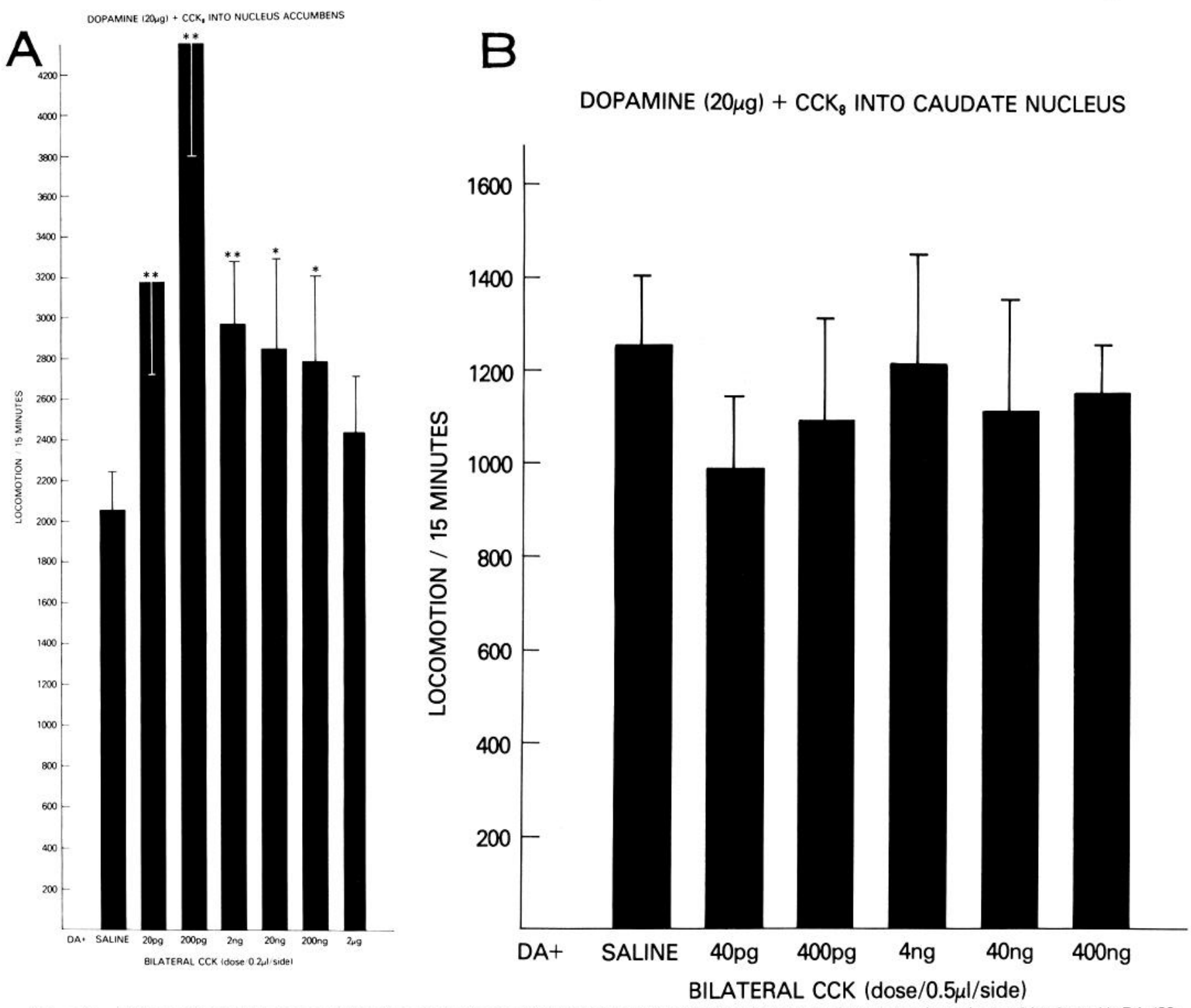

Figure 5. CCK significantly increased DA-induced hyperlocomotion when CCK was injected into the nucleus accumbens in combination with DA (20 $\mu \mathrm{g} / \mathrm{side}$ ) (ANOVA: $F_{6,48}=4.46, p<0.01$, Newman-Keuls $\mathrm{p}<.05(*), p<0.01(* *)$ as compared to DA $(20 \mu \mathrm{g} /$ side) + saline). CCK had no effect on locomotion when injected into the caudate nucleus in combination with DA $(20 \mu \mathrm{g} / \mathrm{side}) . N=8$ for each dose of each treatment.

behavioral effects of systemically administered APO on stereotypy when injected into the nucleus accumbens of awake rats. Effective doses of CCK ranged from $20 \mathrm{pg}$ to $200 \mathrm{ng}$, which are within the range of concentrations that have been reported for endogenous CCK in the nucleus accumbens (Beinfeld and Palkovits, 1981). The facilitatory effects of CCK appear to occur at physiologically relevant concentrations.

CCK did not show any effects on locomotion or stereotypy when administered alone into the nucleus accumbens, over a wide dose range. CCK, therefore, does not appear to have any direct postsynaptic activity in the nucleus accumbens which would be equivalent or analagous to the postsynaptic actions of DA on the behaviors tested. This finding leads to the suggestion that CCK may act primarily as a modulator of DA in the nucleus accumbens.

CCK had no effect on stereotypy when administered alone into the caudate nucleus, or in conjunction with intracerebral DA or systemic APO. Stereotyped sniffing has been considered as primarily a nigrostriatal behavior (Creese and Iversen, 1974; Iversen, 1977; Joyce, 1983). More recent evidence suggests that stereotypy can also be elicited from the nucleus accumbens (Costall and Naylor, 1975; Costall et al., 1977; Joyce, 1983). The mechanism of action of elicitation of stereotypy may involve a feedback pathway from the caudate nucleus to the nucleus accumbens (Costall et al., 1977). The use of stereotypy tests in the present paradigm for both the caudate nucleus and the nucleus accumbens was based on these recent findings. The ability of CCK injected into the nucleus accumbens to potentiate APO-induced stereotypy lends further support to a role for the nucleus accumbens in stereotyped behaviors.

The lack of effect of CCK alone in the caudate nucleus, and in combination with systemic APO, provides evidence that CCK does not potentiate behaviors mediated by a dopaminergic agonist in the caudate nucleus. However, the inability of the combination of CCK + DA to induce hyperlocomotion when injected into the caudate nucleus cannot be considered definitive, since DA at $20 \mu \mathrm{g} / \mathrm{side}$ did not produce hyperlocomotion in the caudate nucleus. Hyperlocomotion is thought to be mediated primarily in the mesolimbic projection to the nucleus accumbens rather than the caudate nucleus (Pijnenburg and van Rossum, 1973; Costall and Naylor, 1975; Costall et al., 1977; Iversen, 1977). A pilot dose-response study of DA injected into the caudate nucleus did not show any doses of DA which induced hyperlocomotion. It is possible that some combination of CCK and DA doses might have an effect on locomotion when 
$\mathrm{CCK}_{8}$ INTO NUCLEUS ACCUMBENS:

APOMORPHINE PRETREATMENT
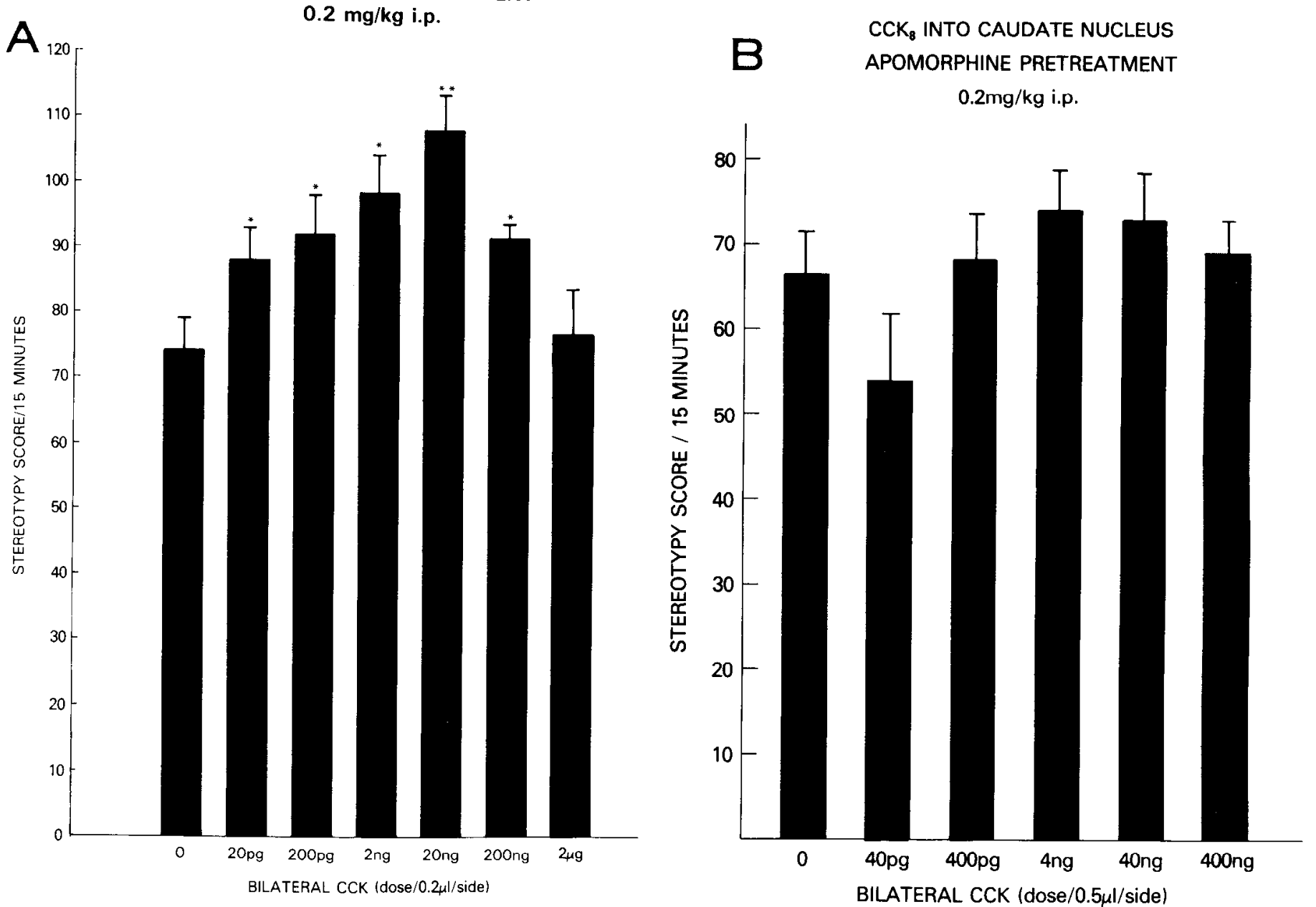

Figure 6. A, CCK significantly increased APO-induced stereotypy when CCK was injected into the nucleus accumbens $15 \mathrm{~min}$ after APO (0.2 mg/kg, s.C.) (ANOVA: $F_{6,48}=7.64, p<0.01$, Newman-Keuls $p<0.05(*), p<0.01(* *)$ as compared to APO $(0.2 \mathrm{mg} / \mathrm{kg}$, s.C.) + saline). $B$, CCK had no effect on stereotypy when injected into the caudate nucleus $15 \mathrm{~min}$ after APO $(0.2 \mathrm{mg} / \mathrm{kg}$, s.c. $) . N=8$ for each dose of each treatment

injected into the caudate nucleus. The main finding at present, however, indicates that CCK does not increase or decrease stereotyped behaviors most closely linked to the caudate nucleus. If further studies confirm the ability of CCK to potentiate behavioral effects of DA and dopaminergic agonists in the nucleus accumbens, but not in the caudate nucleus, the present paradigm could be used to test other anatomical regions receiving terminals from the CCK/ DA-containing neurons in the ventral tegmentum, such as the olfactory tubercles, the prefrontal cortex, and the amygdala.

Unsultated CCK had no effect on DA-induced hyperlocomotion or APO-induced stereotypy in the nucleus accumbens. This lack of effect does not appear to be a function of a potency differential, since a dose three orders of magnitude above effective sulfated CCK doses was also without effect. Receptor-binding studies of CCK in the brain report no difference, or only one order of magnitude difference, between sulfated and unsulfated forms of CCK (Hays et al., 1980; Innis and Snyder, 1980; Van Dijk et al., 1984). Behavioral studies have reported either no difference or small differences in effects of sulfated and unsulfated CCK (Itoh and Katsuura, 1981; Jurna and Zetler, 1981; Kovacs et al., 1981). The present study provides evidence for a modulatory function of CCK on dopaminergic activity which is specific for the sulfated form of the octapeptide.

Two pharmacological antagonists of CCK blocked the facilitatory effect of CCK on dopaminergic actions, indicating some degree of pharmacological specificity for the CCK effect. Proglumide is a glutaramic acid derivative developed as a specific antagonist of CCK at receptors in the pancreas and gall bladder. Proglumide was shown to block the physiological effects of CCK in stimulating release of pancreatic amylase (Gardner et al., 1977; Hahne et al., 1981). Proglumide has also been shown to block behavioral effects of peripherally and centrally administered CCK (Collins et al., 1983; Hoebel and Aulisi, 1984; Schneider et al., 1985) and electrophysiological effects of centrally administered CCK (Chiodo and Bunney, 1983). In the present paradigm, proglumide blocked the ability of CCK to enhance DA-induced hyperlocomotion when injected directly into the nucleus accumbens. The effective dose for this action of proglumide was $20 \mu \mathrm{g}$, as compared to the minimum effective dose of CCK, $20 \mathrm{pg}$. Proglumide does not appear to be a potent antagonist of CCK in this paradigm. However, it may be pharmacologically specific, since proglumide injected alone, or in combination with DA, had no effect on either spontaneous locomotion or on DA-induced hyperlocomotion.

Antiserum raised against sulfated CCK-8 provides an immunologically determined, pharmacologically specific antagonist of CCK. Undiluted antiserum and 1:5 diluted antiserum effectively blocked the actions of CCK on DA-induced hyperlocomotion. Preimmune serum, tested as a control for nonspecific effects of serum injected into the nucleus accumbens, had no effect on the actions of CCK. As with proglumide, CCK antibodies had no effect on spontaneous locomotion and did not effect DA-induced hyperlocomotion, indicating pharmacologic specificity to the facilatatory effects of CCK. The 


\section{INACTIVITY OF UNSULFATED $\mathrm{CCK}_{8}$ IN THE NUCLEUS ACCUMBENS}

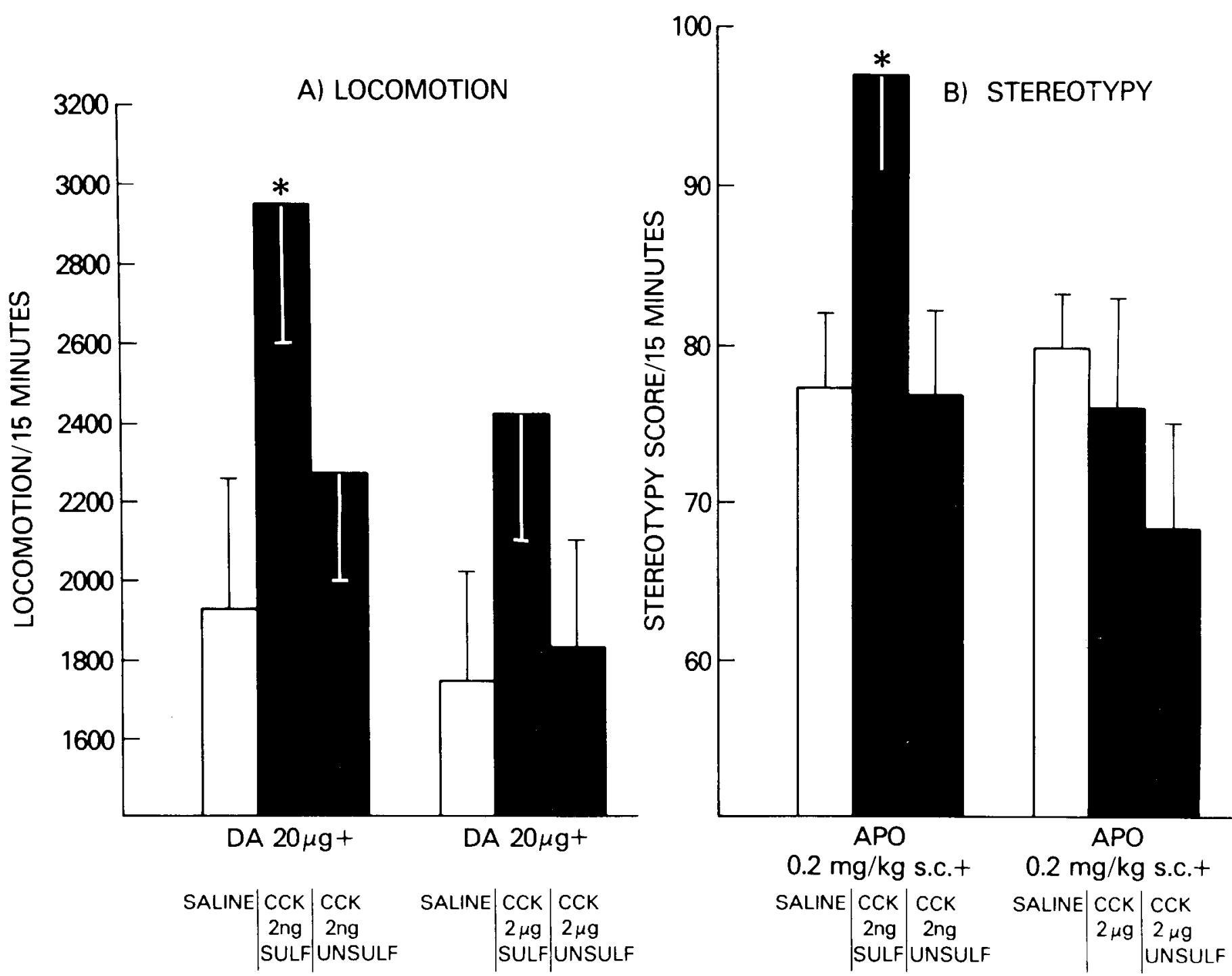

Figure 7. Unsulfated CCK, 2 ng/side, injected into the nucleus accumbens had no effect on DA-induced hyperlocomotion ( $A$ ) or APO-induced stereotypy $(R)$, as compared to $D A(20 \mu g)+$ saline or to APO $(0.2 \mathrm{mg} / \mathrm{kg}$, s.c. $)+$ saline. Sulfated CCK potentiated DA-induced hyperlocomotion and $A P O$ induccd stereotypy at this dose $(*, p<0.05$ by grouped $t$ test statistics). Unsulfated CCK at $2 \mu \mathrm{g} / \mathrm{side}$, a dose 1000 -fold higher than the active dose of sulfated CCK, also had no effect on DA-induced hyperlocomotion or APO-induced stereotypy. $N=6$ for each dose of each treatment.

fact that these two antagonists block only the facilitatory effects of CCK increases the likelihood that CCK is not exerting a nonspecific peptide effect.

A biphasic dose-response curve was seen for the potentiating effects of CCK on DA-induced hyperlocomotion and APO-induced stereotypy in the nucleus accumbens. The highest dose of CCK tested, $2 \mu \mathrm{g}$, failed to show the potentiation effect. Higher doses of CCK were not tested, due to difficulty in dissolving greater quantities of CCK in the $0.2-\mu \mathrm{l}$ volume required for intra-accumbens injection. It is likely that doses of CCK above $2 \mu \mathrm{g}$ could have effects opposite to those of picogram and nanogram doses. Electrophysiological studies demonstrated that high doses of CCK produce depolarization block, causing a temporary cessation of firing of ventral teg mental neurons (Skirboll et al, 1981; White and Wang, 1984).

Several previous behavioral studies have investigated interactions between CCK and DA in the mesolimbic system. Early studies employed injections of microgram quantities of CCK in combination with DA, amphetamine, or APO (Kovacs et al., 1981; Ellinwood et al., 1983; Schneider et al., 1983; Widerlov et al., 1983; Hamilton et al., 1984). These publications reported either no change or inhibition of DA-mediated behaviors by CCK. Since microgram doses of CCK are within the range which induces depolarization block (Skirboll et al., 1981; White and Wang, 1984), it is likely that the behavioral studies cited would yield data resembling the extreme right of the dose-response curve of Figures 5 and 6 of the present study. Facilitatory effects of picogram and nanogram doses of CCK, used in the present paradigm, may more accurately reflect the physiologically relevant actions of endogenous CCK.

In another recent behavioral study, CCK was administered into the nucleus accumbens 60 min before testing ( $V$ an Ree et al., 1983). An inhibition of APO-induced behaviors by CCK was reported. CCK is a relatively labile peptide, with a half-life in vivo between 10 (I onovics et al., 1979) and 52 min (Deschodt-Lanckman et al., 1981). The breakdown products of CCK 8 are reported to include smaller fragments such as CCK-4 (Deschodt-Lanckman et al., 1981). CCK-4 has been reported to have behavioral effects opposite to the behavioral effects of CCK-8 on open field behaviors ( $\mathrm{Hsiao}$ et al., 1984). It is possible, therefore, that behavioral testing begun at a time point considerably after injection of CCK could yield different results due to formation of active metabolites of CCK. A complete time course for the actions of CCK is required to test this hypothosis. 

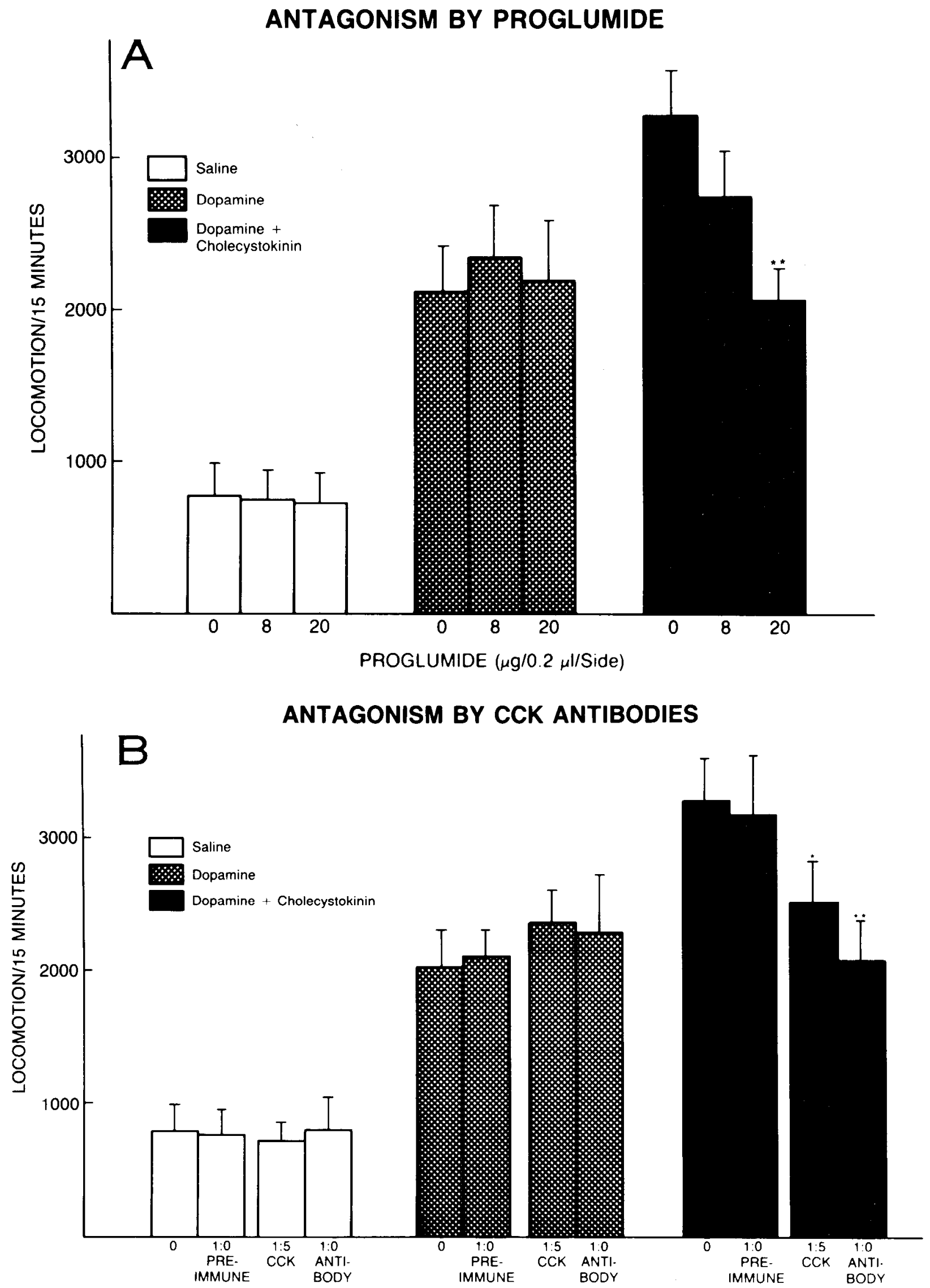

ANTISERUM $(0.2 \mu \mathrm{l} / \mathrm{Side})$

Figure 8. A, Proglumide, a relatively specific antagonist of the peripheral CCK receptor, blocked the ability of CCK (200 pg/side) to potentiate DAinduced hyperlocomotion in the nucleus accumbens (ANOVA: $F_{2,15}=5.21, \rho<0.05$; Newman-Keuls $p<0.05$ ( $*$ ) for proglumide, $20 \mu \mathrm{g} / \mathrm{side}$ ), as compared to saline + DA $(20 \mu \mathrm{g})+\mathrm{CCK}(200 \mathrm{pg})$. Proglumide had no effect on DA-induced hyperlocomotion or on base line locomotion at the doses tested. $N=6$ for each dose of each treatment. $B$, Rabbit antiserum undiluted or diluted 1.5 in saline, raised against sulfated CCK 8 , blocked the ability of CCK (200 pg/ side) to potentiate DA-induced hyperlocomotion in the nucleus accumbens (ANOVA: $F_{3,20}=7.24, p<0.01(* *)$, Newman-Keuls $p<0.05(*)$, as compared to saline + DA $(20 \mu \mathrm{g} / \mathrm{side})+\mathrm{CCK}(200 \mathrm{pg} / \mathrm{side})$. Preimmune undiluted serum had no effect on the CCK-induced increase in DA-induced hyperlocomotion. Preimmune serum and antiserum had no effect on DA-induced hyperlocomotion or on base line locomotion. 
To determine definitively the functional specificity of CCK in potentiating dopamine-induced behaviors in the nucleus accumbens, other peptides can be tested in the present paradigm. Several studies have addressed the question of peptides interacting with DA in the nucleus accumbens. Nemeroff et al. (1983) demonstrated that neurotensin microinjected into the nucleus accumbens antagonizes DA-induced increases in locomotion and rearing. Kalivas et al. (1984) have demonstrated that methionine-enkephalin increases locomotor activity when injected into the nucleus accumbens, either alone or in combination with DA. Since the nucleus accumbens contains a large number of neuropeptides, it is not surprising that other peptides influence dopaminergic functions. CCK appears to be the first peptide demonstrated to increase the response to dopaminergic functions, without having an effect alone. However, the functional specificity of this CCK-DA interaction must be further explored with a variety of neuropeptides.

In conclusion, CCK microinfused into the nucleus accumbens potentiated DA-induced hyperlocomotion and APO-induced stereotypy. The potentiation was blocked by the CCK receptor antagonist, proglumide, and by rabbit antiserum raised against CCK. Unsulfated CCK was ineffective in this paradigm. CCK had no effect alone on locomotion or stereotypy, suggesting that, behaviorally, CCK acts as a modulator of dopaminergic function. The mechanism of action for the observed modulation is unknown. Possibilities include postsynaptic receptors in the nucleus accumbens, where a CCK-binding site could be linked to a DA receptor, or an interaction between CCK and DA at a presynaptic uptake or release site in the nucleus accumbens. CCK microinfused into the caudate nucleus did not affect APO-induced stereotypy and did not have any effect alone on stereotypy or locomotion. Since CCK and DA are known to coexist in the mesolimbic pathway from the ventral tegmental neurons to the nucleus accumbens, but are located in separate neurons in the substantia nigra and in the caudate nucleus (Hökfelt et al., $1980 \mathrm{a}, \mathrm{b})$, the CCK-DA behavioral facilitation phenomenon may represent a mechanism specific to a site of coexistence.

\section{References}

Agnati, L. F., K. Fuxe, F. Benfenati, M. F. Cleani, N. Battistini, V. Mutt, L. Cavicchiołi, G. Galli, and T. Hökfelt (1983) Differential modulation of CCK 8 and $\mathrm{CCK}-4$ of ${ }^{3} \mathrm{H}$-spiperone binding sites linked to dopamine and 5 . hydroxytryptamine receptors in the brain of the rat. Neurosci. Lett. 35. 179-183.

Beinfeld, M. C., and M. Palkovits (1981) Distribution of cholecystokinin (CCK) in the hypothalamus and limbic system of the rat. Neuropeptides 2: 123129.

Chesselet, M. F. (1984) Presynaptic regulation of neurotransmitter release in the brain: Facts and hypothesis. Neuroscience 12: 347-375

Chiodo, L. A., and B. S. Bunney (1983) Proglumide: Selective antagonism of excitatory effects of cholecystokinin in central nervous system. Science 219: $1449-1451$.

Cohen, S. L., M. Knight, C. A. Tamminga, and T. N. Chase (1983) Minimized tolerance to the suppressive effects of CCK-8 on operant responding. Behav. Neural Biol. 39: 123-127.

Collins, S., D. Walker, P. Forsyth, and L. Belbeck (1983) The effects of proglumide on cholecystokinin-, bombesin-, and glucagon-induced satiety in the rat. Life Sci. 32: 2223-2229

Costall, B., and R. J. Naylor (1975) The behavioural effects of dopamine applied intracerebrally to areas of the mesolimbic system. Eur. J. Pharmacol. 32: 87-92

Costall, B., R. J. Naylor, J. G. Cannon, and T. Lee (1977) Differentiation of the dopamine mechanisms mediating stereotyped behaviour and hyperactivity in the nucleus accumbens and caudate-putamen. J. Pharm. Pharmacol. 29: 337-342

Crawley, J. N., J. A. Rojas-Ramirez, and W. Mendelson (1982) The role of central and peripheral cholecystokinin in mediating appetitive behaviors. Peptides 3: 535-538.

Crawley, J. N., D. W. Hommer, and L. R. Skirboll (1984) Behavioral and neurophysiological evidence for a facilatory interaction between co-existing transmitters: Cholecystokinin and dopamine. Neurochem. Int. 6: 755-760.

Creese, 1., and S. D. Iversen (1974) The role of forebrain dopamine systems in amphetamine induced stereotyped behavior in the rat. Psychopharmacologia 39: 345-357.

DeFrance, J., R. W. Sikes, and R. B. Chronister (1984) Effects of CCK-8 in the rucleus accurnbers. Peptides 5: 1-6.

Deschodt-Lanckman, M., N. D. Bvi, M. Noyer, and J. Christophe (1981) Degradation of cholecystokinin-like peptides by a crude rat brain synaptosomal fraction: A study by high pressure liquid chromatography. Regul. Pept. 2: 15-30.

Ellinwood, E. H., K. Rockwell, and N. Wagoner (1983) Apomorphine behavioral effect is facilitated by dibutyryl/CAMP and inhibited by caerulein Psychopharmacol. Bull. 19: 352-354.

Fallon, J. H., R. Hicks, and S. E. Loughlin (1983) The origin of cholecystokinin terminals in the basal forebrain of the rat: evidence from immunofluorescence and retrograde tracing. Neurosci. Lett. 37: 29-35.

Faris, P. L., B. R. Komisaruk, L. R. Watkins, and D. J. Mayer (1983) Evidence for the neuropeptide cholecystokinin as an antagonist of opiate analgesia. Science 219: 310-312

Fisher, R. A. (1950) Contributions to Mathematical Statistics, p. 17.510 , John Wiley \& Sons, Inc., New York.

Frey, P. (1983) Cholecystokinin octapeptide levels in rat brain are changed after subchronic neuroleptic treatment. Eur. J. Pharmacol. 95: 87-92.

Fuxe, K. K. Andersson, V. Locatelli, L. F. Agnati, J. Hökfelt, L. Skirboll, and $V$. Mutt (1980) Cholecystokinin peptides produce marked reduction of dopamine turnover in discrete areas in the rat brain following intraventricular injection. Eur. J. Pharmacol. 67: 329-331.

Gardner, J. D., J. P. Christophe, T. P. Conlon and E. K. Frandsen. (1977) Initial steps in the action of cholecystokinin and cholinergic agents on pancreatic acinar cells. In First International Symposium on Hormonal Receptors in Digestive Tract Physiology, S. Bonfils, P. Fromageol, and G. Rosselin, eds., pp. 237-246, Elsevier Biomedical Press, New York.

Gilles, C., F. Lotstra, and J. J. Vanderhaeghen (1983) CCK nerve terminals in the rat striatal and limbic areas originate partly in the brain stem and partly in telencephalic structures. Life Sci. 32: 1683-1690.

Hahne, W. F., R. T. Jensen, G. F. Lemp, and J. D. Gardner (1981) Proglumide and benzotript: Members of a different class of cholecystokinin receptor antagonists. Proc. Natl. Acad. Sci. U. S. A. 78: 6304-6308.

Hamilton, M., M. J. Sheehan, J. de Belleroche, and L. J. Herberg (1984) The cholecystokinin analogue, caerulein, does not modulate dopamine release or dopamine-induced locomotor activity in the nucleus accumbens of rat. Neurosci. Lett. 44: 77-82

Hays, S. E., M. C. Beinfeld, R. T. Jensen, F. K. Goodwin, and S. M. Paul (1980) Demonstration of a putative receptor site for cholecystokinin in rat brain. Neuropeptides 1: 53-62.

Hoebel, B. G., and E. Aulisi (1984) Cholecystokinin self-injection in the nucleus accumbens and block with proglumide. Soc. Neurosci. Abstr. 10 : 652.

Hökfelt, T., J. F. Rehfeld, L. Skirboll, B. Ivemark, M. Goldstein and K. Markey (1980a) Evidence for coexistence of dopamine and CCK in meso-limbic neurones. Nature 285: 476-478.

Hökfelt, T., L. Skirboll, J. F. Rehfeld, M. Goldstein, K. Markey, and O. Dann (1980b) A subpopulation of mesencephalic dopamine neurons projecting to limbic areas contains a cholecystokinin-like peptide: Evidence from immunohistochemistry combined with retrograde tracing. Neuroscience 5: 2093-2124.

Hommer, D. W., and L. R. Skirbolt (1983) Cholecystokinin-like peptides potentiate apomorphine-induced inhibition of dopamine neurons. Eur. J. Pharmacol. 97: 151-152.

Hsiao, S., G. Katsuura, and S. Itoh (1984) Cholecystokinin tetrapeptide, proglumide and open-field behavior in rats. Life Sci. 34: 2165-2168.

Innis, R. B., and S. H. Snyder (1980) Cholecystokinin receptor binding in brain and pancreas: Regulation of pancreatic binding by cyclic and acyclic guanine nucleotides. Eur. J. Pharmacol. 65: 123-124

Itoh, S., and G. Katsuura (1981) Suppressive action of cholecystokininoctapeptide on the behavioral effects of L-DOPA in the rat. Eur. J. Pharmacol. 75: 313316 .

Iversen, S. D. (1977) Brain dopamine systems and behavior In Handbook of Psychopharmacology, L. L. Iversen, S. D., Iversen and S. H. Snyder, eds., Vol. 8, pp. 333-384, Plenum Press, New York.

Joyce, J. N. (1983) Multiple dopamine receptors and behavior. Neurosci. Biobehav. Rev. 7: 227-256.

Jurna, I., and G. Zetler (1981) Antinociceptive effect of centrally administered caerulein and cholecystokinin octapeptide (CCK-8). Eur. J. Pharmacol. 73 : 323-331

Kalivas, P. W. D. Stanley, E. Widerlov, G. Breese, and A. J. Prange (1984) Enkephalin action on the mesolimbic system: A dopamine-dependent and 
a dopamine independent increase in locomotor activity. J. Pharmacol. Exp. Ther., in press.

Katsuura, G., S. Itoh, and J. F. Rehfeld (1984) Effects of cholecystokinin on apomorphine-induced changes of motility in rats. Neuropharmacology 23: $731-734$.

Kovacs, G. L., G. Szabo, B. Penke, and G. Telegdy (1981) Effects of cholecystokinin octapeptide on striatal dopamine metabolism and on apomorphine-induced stereotyped cage-climbing in mice. Eur. J. Pharmacol. 69: 313-319

Lonovics, J., F. Hajnal, P. Mara, I. Szabo, and V. Varro (1979) Investigation of cholecyotokinin-octapeptide splitting enzyme in the dog kidney. ACTA Hepato-Gastroenterol. 26: 222-226.

Markstein, R., and T. Hökfelt (1984) Effect of cholecystokinin-octapeptide on dopamine release from slices of cat caudate nucleus. J. Neurosci. 4:570575

Marley, P. D., P. C. Emson, and J. F. Rehfeld (1982) Effect of 6-hydroxydopamine lesions of the medial forebrain bundle on the distribution of cholecystokinin in rat torebrain. Brain Res. 252: 382-385.

Meyer, D. K., and J. Krauss (1983) Dopamine modulates cholecystokinin release in neostriatum. Nature $301: 338-340$

Morley, J. E. (1982) The ascent of cholecystokinin (CCK)-from gut to brain. Life Sci. 30: $479-493$

Murphy, R. B., and D. I. Schuster (1982) Modulation of ${ }^{3} \mathrm{H}$-dopamine binding by cholecystokinin octapeptide (CCK-8). Peptides 3: 539-543.

Mutt, V. (1978) Hormone isolation. In Gut Hormones, S. R. Bloom, ed., pp. 21-27, Churchill, London

Myers, R. D. (1966) Injection of solutions into cerebral tissue: Relation between volume and diffusion. Physiol. Behav. 1: 171-174.

Nemeroff, C. B., D. Luttinger, D. E. Hernandez, R. B. Mailman, G. A. Mason, C. A. Kilts, K. Beaumont, G. R. Breese, and A. J. Prange (1983) Interactions of neurotensin with brain dopamine systems: Biochemical and behavioral studies. J. Pharmacol Exp. Ther. 225: 337-345.

Passaro, E., H. Debas, W. Oldendorf, and T. Yamada (1982) Rapid appearance of intraventricularly administered neuropeptides in the peripheral circulation. Brain Res. 241: 335-340.

Paxinos, G., and C. Watson (1982) The Rat Brain in Stereotaxic Coordinates, Academic Pross, Inc., New York.

Pijnenburg, A. J. J., and J. M. van Rossum (1973) Stimulation of locomotor activity following injection of dopamine into the nucleus accumbens. J. Pharm. Pharmacol. 25: 1003-1005

Praissman, M. P. A. Martinez, C. F. Saladino, J. M. Berkowitz, A. W. Steggles, and J. A. Finkelstein (1983) Characterization of cholecystokinin binding sites in rat cerebral cortex using a ${ }^{125}$-CCK-8 probe resistant to degradation. J. Neurochem. 40: 1406-1413.

Saito, A., H. Sankaran, I. D. Goldfine, and J. A. Williams (1980) Cholecystokinin receptors in brain: Characterization and distribution. Science 208. 1155-1156.

Schneider, L. H., J. E. Alpert, and S. D. Iversen (1983) CCK-8 modulation of mesolimbic dopamine: Antagonism of amphetamine-stimulated behaviors. Peptides 4: 749-753.

Skirboll, L. R., A. A. Grace, D. W. Hommer, J. Rehfeld, M. Goldstein, T. Hökfelt, and B. S. Bunney (1981) Peptide-monoamine coexistence: Studies of the actions of cholecystokinin-like peptide on the electrical activity of midbrain dopamine neurons. Neuroscience 6: 2111-2124.

Smith, G. P., and J. Gibbs (1981) Brain-gut peptides and the control of food intake. pp. 389-395, In Neurosecretion and Brain Peptides, J. B. Martin, S. Reichlin, and K. L. Bick, eds., pp. 389-395, Raven Press, New York.

Studler, J. M., H. Simon, F. Cesselin, J. C. Legrand, J. Glowinski, and J. P. Tassin (1981) Biochemical investigation on the localization of the cholecystokinin octapeptide in dopaminergic neurons originating from the ventral tegmental area of the rat. Neuropeptides 2: 131-139.

Van Dijk, A., J. G. Richards, A. Trzeciak, D. Gillessen, and H. Möhler (1984) Cholecystokinin receptors: Biochemical demonstration and autoradiographical localization in rat brain and pancreas using $\left[{ }^{3} \mathrm{H}\right]$ cholecystokinin 8 as radioligand. J. Neurosci. 4: 1021-1033

Van Ree, J. M., O. Gaffori, and D. DeWied (1983) In rats, the behavioral profile of CCK. 8 related peptides resembles that of antipsychotic agents. Eur. J. Pharmacol. 93: 63-78.

Voigt, M. M., and R. Y. Wang (1984) In vivo release of dopamine in the nucleus accumbens of the rat: Modulation by cholecystokinin. Brain Res. 296: 189-193.

Watkins, L. R., I. B. Kinscheck, and D. J. Mayer (1984) Potentiation of opiate analgesia and apparent reversal of morphine tolerance by proglumide. Science 224:395-396

White, F. J., and R. Y. Wang (1984) Interactions of cholecystokinin octapeptide and dopamine on nucleus accumbens neurons. Brain Res. 300: 161166.

Widerlov, E., P. W. Kalivas, M. H. Lewis, A. J. Prange, and G. R. Breese (1983) Influence of cholecystokinin on central monoaminergic pathways. Regul. Pept. 6. 99-109.

Zetler, G. (1980) Effects of cholecystokinin-like peptides on rearing activity and hexobarbital.induced sleep. Eur. J. Pharmacol. 66: 137-139.

Zetler, G. (1982) Caerulein and cholecystokinin octapeptide (CCK-8): Sedative and anticonvulsive effects in mice unaffected by the benzodiazepine antagonist Rol5-1788. Neurosci. Lett. 28: 287-290. 